\title{
The Association between Venous Thromboembolism and Lipid Profile in a Tunisian Population
}

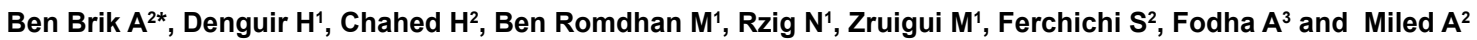

${ }^{1}$ Cardiology Service, Internal Medicine and Biochemistry Laboratory in the Regional Hospital, Tunisia

${ }^{2}$ Biochemistry Laboratory in University Hospital, Tunisia

${ }^{3}$ Cardiology Service in University Hospital Complex, Tunisia

\begin{abstract}
Background and objectives: Lipids and lipoproteins modulate the expression and/or the function of thrombotic, fibrinolytic and rheological factors among patients with cardiovascular disease. Many studies have suggested a link between risk factors of venous thromboembolism (VTE) and dyslipidemia but results are heterogeneous. We sought to identify if dyslipidemia is a risk factor of VTE disease.
\end{abstract}

Patients and methods: We have developed an hospital-based case-control study which was conducted in 32 patients with VTE and 33 age- and gender-matched healthy controls. We were proceeding to compare the lipid profile of the two groups after analysing the total cholesterol, triglycerides, high density lipoprotein cholesterol (HDL-C), low density lipoprotein cholesterol (LDL-C), Lipoprotein Lp(a), Apo-A1, Apo-B and Apo-E. Patients who have cancer and whose taken statins or fibrates are excluded.

Results: The two groups have the same demographic characteristics but there were more diabetics, arterial hypertension and obese in the VTE group than the control group respectively (Diabetic: $37 \%$ vs. 18\%, hypertension: $68.6 \%$ vs. $15.2 \%$ and (body mass index) $\mathrm{BMI} \geq 30 \mathrm{Kg} / \mathrm{m}^{2}: 43.8 \%$ vs. $18.2 \%$ ). The mean value of the total cholesterol (TC), the LDL-C, Lipoprotein Lp (a), and Apo-B were statistically higher in the VTE group compared to control group respectively ; TC (4.942 \pm 1.409 vs. $4.362 \pm 0.872 \mathrm{mmol} / \mathrm{L}, \mathrm{P}=0.049)$, LDL-C (3.114 $\pm 1.100 \mathrm{vs.} 2.602 \pm 0.695$ $\mathrm{mmol} / \mathrm{L}, \mathrm{P}=0.001)$, Lp (a) $(0.205 \pm 0.115$ vs. $0.0819 \pm 0.0479 \mathrm{~g} / \mathrm{l}, \mathrm{P}<10-3)$, Apo-B (1.333 \pm 0.253 vs. $0.8006 \pm 0.238$ $\mathrm{g} / \mathrm{l}, \mathrm{P}<10-3)$, but there was no statistical significant difference was observed between the two groups in the value of Triglycerides and Apo E respectively $(1.710 \pm 0.816$ vs. $1.366 \pm 0.636 \mathrm{mmol} / \mathrm{L}, P=0.62),(0.102 \pm 0.070$ vs. 0.0810 $\pm 0.153 \mathrm{~g} / \mathrm{l}, \mathrm{P}=0.48$ ).

However, the mean value of HDL-C and Apo-A1 were statically lower in the VTE group; HDL-C $(1.048 \pm 0.237$ vs. $1.473 \pm 0.334 \mathrm{mmol} / \mathrm{L}, \mathrm{P}<0.001)$ and Apo-A1 (1.010 \pm 0.2437 vs. $\left.1.414 \pm 0.2911 \mathrm{~g} / \mathrm{l}, \mathrm{P}<10^{-3}\right)$. Furthermore, enhanced HDL-C $\leq 0.906 \mathrm{mmol} / \mathrm{L}$ was diagnosed in 21 patients $(65.6 \%)$ in the VTE group versus 4 patients $(12.1 \%)$ in the control group $(\mathrm{P}<0.001)$, so it was also independently associated with a risk of VTE.

Conclusion: The present study shows a significant association between the occurrence of venous thromboembolism and lower levels of HDL-C and ApoA1 and higher levels of LDL-C, Apo-B and Lp(a), but, there were no effect of Triglycerides and ApoE. Nevertheless, these results must be confirmed with a large population study to prove an eventual independent factor for VTE and dyslipidemia.

Keywords: VTE; DVT; Idiopathic; Reccurence; Apolipoprotein; $\operatorname{Lp}(\mathrm{a})$

\section{Introduction}

Venous Thromboembolism (VTE) is the union of deep vein thrombosis (DVT) and pulmonary embolism (PE) [1]; it's an important cause of morbidity and mortality with an estimated annual incidence of 0.67 to 1.0 per 1000 among the general population in western countries [2]. It is a polygenic disease with pathogenic contributions from both genetic and environmental risk factors; according to Virchow's triad, VTE results from stasis(immobility, polycythemia), hypercoagulability (hereditary: factor V Leiden, Protein C and S deficiency ..., Acquired: cancer, obesity, chemotherapy, pregnancy..) and the alteration in the blood vessel wall(smoking, hypertension, catheter, surgery...) [3].

This dichotomy has been challenged in recent years, it still many unknown risk factors. Lipids and lipoproteins modulate the expression and/or the function of thrombotic, fibrinolytic and rheological factors among patients with cardiovascular disease [4]. Many studies have suggested a link between risk factors of VTE and dyslipidemia but results are heterogeneous. We sought to identify if dyslipidemia is a risk factor of VTE disease (Figure 1).

\section{Signs and symptoms of thromboembolism}

Signs and symptoms of thromboembolism include the following:

- Acute onset of shortness of breath; dyspnea is the most frequent symptom of PE

- Pleuritic chest pain, cough, or hemoptysis (with a smaller PE near the pleura)

- Syncope (with a massive PE)

- Sense of impending doom, with apprehension and anxiety

*Corresponding author: Ben Brik A, Biochemistry laboratory, University Hospital, Tunisia, Tel: +21654755816; E-mail: benbrikassia@gmail.com

Received March 23, 2016; Accepted May 26, 2016; Published June 06, 2016

Citation: Ben Brik A, Denguir H, Chahed H, Ben Romdhan M, Rzig N, et al. (2016) The Association between Venous Thromboembolism and Lipid Profile in a Tunisian Population. J Vasc Med Surg 4: 276. doi: 10.4172/2329-6925.1000276

Copyright: (c) 2016 Ben Brik A, et al. This is an open-access article distributed under the terms of the Creative Commons Attribution License, which permits unrestricted use, distribution, and reproduction in any medium, provided the original author and source are credited. 
Citation: Ben Brik A, Denguir H, Chahed H, Ben Romdhan M, Rzig N, et al. (2016) The Association between Venous Thromboembolism and Lipid Profile in a Tunisian Population. J Vasc Med Surg 4: 276. doi: 10.4172/2329-6925.1000276

Page 2 of 5

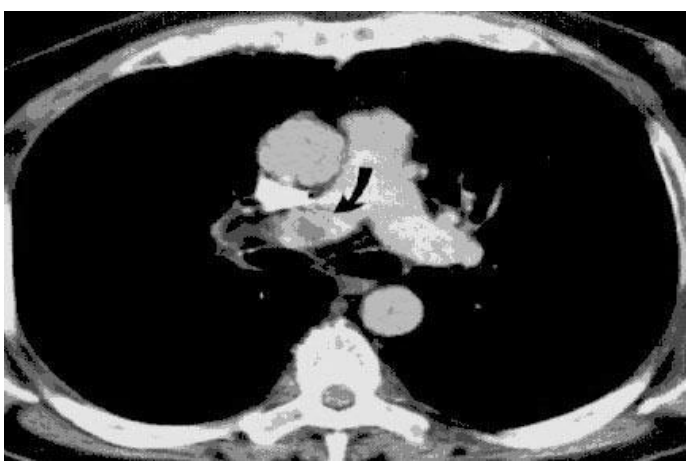

Figure 1: Helical CT scan of the pulmonary arteries. A filling defect in the right pulmonary artery is present, consistent with a pulmonary embolism.

- Complaints related to signs of DVT, lower-extremity swelling, and warmth to touch or tenderness

- Tachypnea (respiratory rate $>18$ breaths $/ \mathrm{min}$ )

- Tachycardia

- Accentuated second heart sound

- Fever

- Normal findings from lung examination

- Cyanosis

\section{Materials and Methods}

\section{Study group}

We have developed a case control study including 2 groups of patients matched in age and sex. The first group of 32 consecutive patients hospitalized for VTE in the cardiology department of Gabes hospital in the south east of Tunisia between January and June 2014. The second group of 33 control healthy peoples without experience of VTE. We proceeded to compare the lipid profile of the two groups after dosing the total cholesterol, triglycerides, high density lipoprotein cholesterol HDL-C, low density lipoprotein cholesterol LDL-C, Lipoprotein Lp (a), ApoA1, ApoB and ApoE.

Patients with experience of cancer and who's taken statin or fibrat are excluded.

\section{Blood collection}

The biochemical analyzes of the total cholesterol, triglycerides, HDL-cholesterol levels were performed in the laboratory of biochemistry at the hospital of Gabes and the biochemical analyzes of Apolipoprotein (Apo-A1, Apo B and Apo E) and Lipoprotein (a) $(\mathrm{Lp}(\mathrm{a}))$ were made in the biochemistry laboratory at the University Hospital "Farhat Hached of Sousse".

Blood samples were obtained by venipuncture in a fasting state, heparinized plasma was centrifuged at $4^{\circ} \mathrm{C}$ and divided into aliquots of $1.0 \mathrm{ml}$, plasma was snapping frozen and stored at $-20^{\circ} \mathrm{C}$ until assay performance the series.

\section{Lipids and Apo lipoproteins measurements}

Glucose, total cholesterol, HDL cholesterol and triglycerides were determined in fresh plasma, using an automated enzymatic method (Beckman coulter (AU480). LDL was calculated using the Friedewald formula with the exception of subjects with plasma triglycerides above ( $4 \mathrm{mmole} / \mathrm{L}$ ). The non-HDL was also calculated because it allow a better estimate of the content in cholesterol of atherogenic lipoproteins and it is considered as the most powerful predictive parameter in the incidence of CVD than LDL-cholesterol. Also calculate ratios CT/ HDL-C and LDL-C/HDL-C.

The automated quantitative determination of Apolipoprotein AI (Apo-AI), the Apolipoprotéin B (Apo-B), the Apolipopotéin E (Apo-E) and lipoprotein (a) in human plasma collected on heparin by immune nephelometry on the $\mathrm{BN}$ Prospec system (Behring) and calculate Apo-B/Apo-AI ratio.

\section{Statistical analysis}

Data were analyzed using SPSS software V18.0. Mean, standard deviation, median percentage and extreme were applied to compare quantitative and qualitative parameters among groups.

An influence of different lipid parameters on the venous thromboembolism was tested using test student. P value less than 0.05 was considered to indicate statistical significance.

\section{Results}

\section{Patients' general characteristics}

Characteristics of patients with VTE and age- and gender-matched controls are shown in Table 1.

The mean age of our patients was (55.86 \pm 19.51 years); $47.7 \%$ of patients were female. The two groups have the same demographic characteristics but there were more diabetics, arterial hypertension and obese in the VTE group than the control group respectively (Diabetic: $37 \%$ vs. $18 \%$, hypertension: $68.6 \%$ vs. $15.2 \%$ and (body mass index) $\mathrm{BMI} \geq 30 \mathrm{Kg} / \mathrm{m}^{2}: 43.8 \%$ vs. $\left.18.2 \%\right)$.

Smoking did not show an association with VTE; there was not statistically significant difference among patients or controls (Table 1).

\section{Patients' groups}

Venous thrombotic events were divided into two groups depending on the location of the thrombus: PE (associated or not with DVT) 21.

\begin{tabular}{|c|c|c|c|}
\hline & $\begin{array}{l}\text { Patient }(\mathrm{N}=32) \\
\text { Number }(\%)\end{array}$ & $\begin{array}{l}\text { Controls }(\mathrm{N}=33) \\
\text { Number }(\%)\end{array}$ & $P$ Value \\
\hline \multicolumn{4}{|c|}{ Gender } \\
\hline Women & $17(53,1 \%)$ & $17(51,5 \%)$ & \\
\hline Men & $15(46,9 \%)$ & $16(48,5 \%)$ & \\
\hline Age: (Means \pm SD) & $54,78 \pm 19,839$ & $56,91 \pm 19,449$ & 0,664 \\
\hline \multicolumn{4}{|c|}{ BMI } \\
\hline $\mathrm{BMI}=30 \mathrm{Kg} / \mathrm{m}^{2}$ & $14(43,8 \%)$ & $6(18,2 \%)$ & 0,013 \\
\hline BMI: $25-30 \mathrm{Kg} / \mathrm{m}^{2}$ & $13(40,6 \%)$ & $15(45,5 \%)$ & \\
\hline $\mathrm{BMI}=25 \mathrm{Kg} / \mathrm{m}^{2}$ & $5(15,6 \%)$ & $12(36,4 \%)$ & \\
\hline \multicolumn{4}{|c|}{ Diabetes: } \\
\hline Diabetic & $12(37,5 \%)$ & $4(12,1 \%)$ & $10^{-3}$ \\
\hline Non Diabetic & $20(62,5 \%)$ & $29(87,9 \%)$ & \\
\hline \multicolumn{4}{|c|}{ Hypertension: } \\
\hline No Hypertension & $10(31,3 \%)$ & $28(84,8 \%)$ & $10^{-3}$ \\
\hline Hypertension & $22(68,6 \%)$ & $5(15,2 \%)$ & \\
\hline \multicolumn{4}{|c|}{ Smoking } \\
\hline Current smokers & $13(40,6 \%)$ & $14(42,4 \%)$ & 0,885 \\
\hline Non Smokers & $19(59,4 \%)$ & $19(57,6 \%)$ & \\
\hline
\end{tabular}

Table 1: Characteristics of patients and controls. 
Citation: Ben Brik A, Denguir H, Chahed H, Ben Romdhan M, Rzig N, et al. (2016) The Association between Venous Thromboembolism and Lipid Profile in a Tunisian Population. J Vasc Med Surg 4: 276. doi: 10.4172/2329-6925.1000276

Page 3 of 5

9\% $(\mathrm{n}=7)$ and DVT or phlebite (78.1\%) $(\mathrm{n}=25)$, (Figure 2). Depending to the presence or absence of recurrence, there are two groups; patients with recurrence phenomenon are $56.3 \%$ of patients group $(n=18)$ and patients with absence of recurrence are $43.8 \%$ of patient group $(n=14)$, (Figure 3). Therefore two groups depending on the presence or absence of risk factors; idiopathic patients are $75 \%$ of the patient group $(n=24)$ and patients who have known risk factors are $25 \%$ of the patient group $(\mathrm{n}=8)$, (Figure 4).

\section{Analysis of Lipoprotein parameters}

There was a statistically significant difference between cases and controls were observed for the total cholesterol ( $4.94 \pm 1.41$ vs. $4.36 \pm$ $0.87 \mathrm{mmol} / \mathrm{L}, \mathrm{P}=0,049)$. VTE cases had a significantly lower mean HDL concentration than controls $(1,048 \pm 0,237$ vs. $1,473 \pm 0,334 \mathrm{mmol} / \mathrm{l}$, $\left.\mathrm{P}=10^{-3}\right)$ but a statistical significant higher mean LDL concentration than controls $(3.11 \pm 1.10$ vs. $2.69 \pm 0.69 \mathrm{mmol} / \mathrm{L}, \mathrm{P}=0,001)$. Triglycerides levels show no statistically significant difference among patients or controls. While non -HDL, was associated with increased plasma concentration in patients groups than controls $(3.89 \pm 1.34$ vs. $2.89 \pm$ $085 \mathrm{mmol} / \mathrm{L}, \mathrm{P}=0,01)$. The TC/HDL-C ratios for VTE patients were significantly higher than for controls $(4.81 \pm 1.41$ vs. $3.17 \pm 0.84, \mathrm{P}=10$ 3 ) also the LDL-C/HDL-C ratio was significantly higher in VTE groups than the control one $\left(3.01 \pm 1.23\right.$ vs. $\left.171 \pm 0.71, \mathrm{P}=10^{-3}\right)$, (Table 2$)$.

The prevalence of HDL-C levels below $(0.91 \mathrm{mmol} / \mathrm{l})$ and LDL-C higher than $4.66 \mathrm{mmol} / \mathrm{l}$

Concerning c-HDL levels below $(0.91 \mathrm{mmol} / \mathrm{l})$, there was a significant difference among patients and controls $\left(\mathrm{P}=10^{-3}\right)$ and the

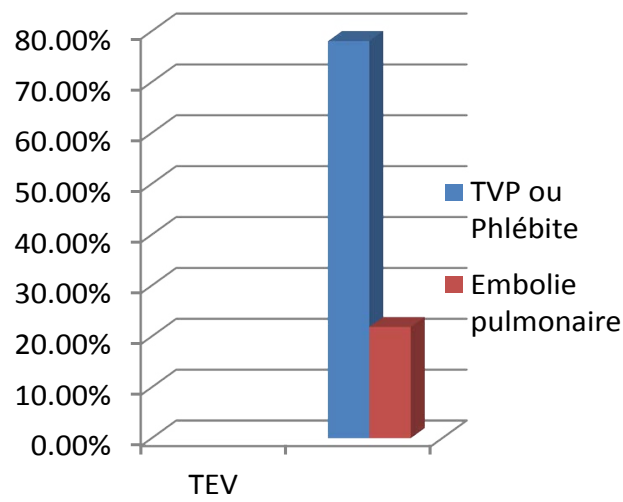

Figure 2: Patients distribution in PE and DVT.

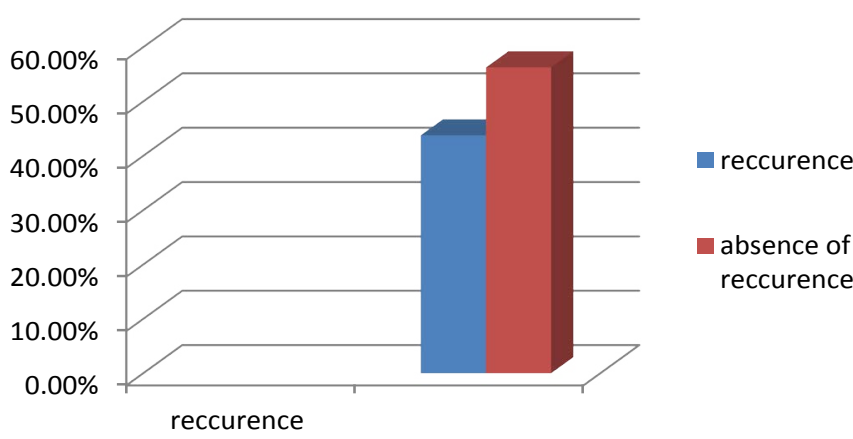

Figure 3: Distribution of patients according to the presence or absence of recurrence.

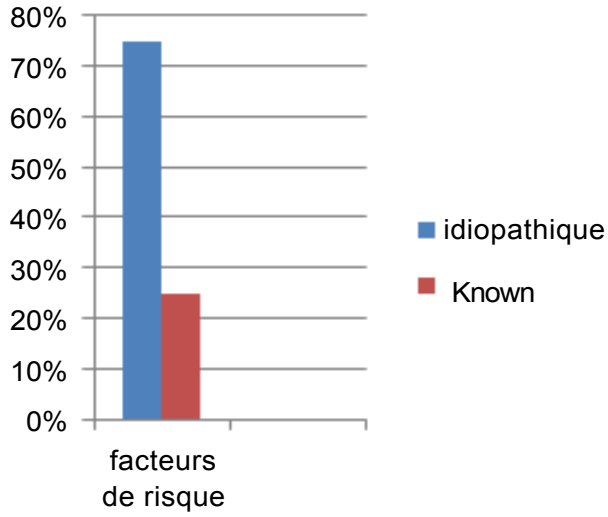

Figure 4: Distribution of patients depending to the presence or absence of the RF.

\begin{tabular}{|c|c|c|c|}
\hline & Patients (mean \pm ET) & Controls (mean \pm ET) & P value \\
\hline Total Cholesterol & $4.94 \pm 1.4$ & $4.36 \pm 0.87$ & 0.05 \\
\hline C-HDL & $1.05 \pm 0.23$ & $1.47 \pm 0.33$ & $10^{-3}$ \\
\hline C-LDL & $3.11 \pm 1.1$ & $2.24 \pm 0.85$ & 0.001 \\
\hline TG & $1.71 \pm 0.81$ & $1.36 \pm 0.63$ & 0.062 \\
\hline Non-HDL & $3.89 \pm 1.34$ & $2.89 \pm 0.85$ & 0.001 \\
\hline CT/HDL & $4.81 \pm 1.4$ & $3.13 \pm 0.83$ & $10^{-3}$ \\
\hline LDL/HDL & $3 \pm 1.23$ & $1.71 \pm 0.71$ & $10^{-3}$ \\
\hline
\end{tabular}

Table 2: Comparison of different lipids among VTE patients and controls.

prevalence of c-LDL levels higher than $4.66 \mathrm{mmol} / \mathrm{l}$ was not significantly different among patients or controls (Table 3 ).

In the patient group, HDL above $0.91 \mathrm{mmol} / \mathrm{l}$, was significantly higher in patients who have idiopathic risk factors than who have known ones $(\mathrm{P}=0.05)$, (Table 4$)$.

\section{Study of Apo lipoproteins}

$\mathrm{Lp}(\mathrm{a})$ levels show astatistically significant difference among patients and controls $\left(0.21 \pm 0.11\right.$ vs. $\left.0.08 \pm 0.05 \mathrm{~g} / \mathrm{l}, \mathrm{P}=10^{-3}\right)$. VTE cases had a significantly lower mean Apo-AI concentration than controls (1.01 \pm 0.24 vs. $\left.1.41 \pm 0.29 \mathrm{~g} / \mathrm{l}, \mathrm{P}=10^{-3}\right)$ although there was a significant higher mean Apo-B concentration than controls $(1.33 \pm 0.25$ vs. $0.80 \pm 0.24$ $\left.\mathrm{g} / \mathrm{l}, \mathrm{P}=10^{-3}\right)$, no statistically significant differences between cases and controls were observed for the Apo-E. The Apo-B/Apo-AI ratios for VTE patients were significantly higher than for controls ( $1.37 \pm 0.46 \mathrm{vs}$. $0.59 \pm 0.18 . \mathrm{P}=10^{-3}$ ), (Table 5).

Apo-AI levels above $1.25 \mathrm{~g} / \mathrm{l}$; there was a statistical significant difference among cases and controls $(\mathrm{P}=0.004)$ also Apo-B levels lower than $1.25 \mathrm{~g} / \mathrm{l}$, have a higher significant difference between cases and controls $\left(\mathrm{P}=10^{-3}\right)$, (Table 6).

\section{Discussion}

There are few studies, as well as conflicting results, demonstrating the influence of different lipid parameters in patients with venous thromboembolism including those with pulmonary embolism and deep venous thrombosis, and to our knowledge it is the first casecontrol study in Tunisia.

Although arterial thrombosis and cardiovascular disease are clearly associated with dyslipidemia and dyslipoprotenemia, but its role in VTE disease is controversial. 


\begin{tabular}{|c|c|c|c|}
\hline & Patients Nobre (\%) & Temoins Nombre (\%) & $P$ Value \\
\hline 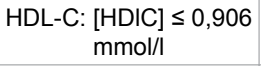 & $21(65,6 \%)$ & $4(12,1 \%)$ & \multirow[t]{2}{*}{$10^{-3}$} \\
\hline$[\mathrm{HDIC}]>0,906 \mathrm{mmol} / \mathrm{l}$ & $11(34,4 \%)$ & $29(87,9 \%)$ & \\
\hline $\begin{array}{c}\text { LDL-C: }[\text { LDLC] } \geq 4,66 \\
\mathrm{mmol} / / \mathrm{l}\end{array}$ & $5(15,6 \%)$ & $1(3 \%)$ & \multirow[t]{2}{*}{0,087} \\
\hline$[\mathrm{LDL}-\mathrm{C}]<4,66 \mathrm{mmol} / \mathrm{l}$ & $27(84,4 \%)$ & $32(97 \%)$ & \\
\hline
\end{tabular}

Table 3: HDL-C and LDL-C distribution between patients and controls.

\begin{tabular}{|c|c|c|c|}
\hline RF & Idiopathic $(\mathbf{n = 2 4 )}$ & Known $(\mathbf{n = 8})$ & P value \\
\hline$[\mathrm{HDL}-\mathrm{C}] \leq 0,906(\mathrm{mmol} / \mathrm{L})$ & $18(75 \%)$ & $5(62,5 \%)$ & \multirow{2}{*}{0,05} \\
\hline$[\mathrm{HDL}-\mathrm{C}]>0,906(\mathrm{mmol} / \mathrm{L})$ & $6(25 \%)$ & $3(37,5 \%)$ & \\
\hline
\end{tabular}

Table 4: HDL-c distribution between patients.

\begin{tabular}{|c|c|c|c|}
\hline & Patients (mean \pm ET) & Temoins (mean \pm ET) & P value \\
\hline Apo-Al & $1.01 \pm 0.24$ & $1.41 \pm 0.29$ & $10^{-3}$ \\
\hline Apo-B & $1.33 \pm 0.25$ & $0.8 \pm 0.23$ & $10^{-3}$ \\
\hline Lp(a) & $0.2 \pm 0.11$ & $0.08 \pm 0.04$ & $10^{-3}$ \\
\hline Apo-E & $0.1 \pm 0.07$ & $0.08 \pm 0.15$ & 0.48 \\
\hline Apo-B/Apo-Al & $1.37 \pm 0.46$ & $0.59 \pm 0.17$ & $10^{-3}$ \\
\hline
\end{tabular}

Table 5: Comparison of Apolipoproteins among VTE patients and controls.

\begin{tabular}{|c|c|c|c|}
\hline & $\begin{array}{c}\text { Patients } \\
\text { Nombre (\%) }\end{array}$ & $\begin{array}{c}\text { Temoins } \\
\text { Nombre (\%) }\end{array}$ & P Value \\
\hline Apo A1: $[$ Apo A1] $\leq 1,25 \mathrm{~g} / \mathrm{l}$ & $25(78,8 \%)$ & $12(36,4 \%)$ & \multirow{2}{*}{0,004} \\
\hline [Apo A1] $1,25 \mathrm{~g} / \mathrm{l}$ & $7(21,2 \%)$ & $21(63,6 \%)$ & \\
\hline Apo B: $[$ Apo B] $] 1,25 \mathrm{~g} / \mathrm{l}$ & $14(43,8 \%)$ & $31(93,9 \%)$ & \\
\hline [Apo B] $\geq 1,25 \mathrm{~g} / \mathrm{l}$ & $18(56,3 \%)$ & $2(6,1 \%)$ & \\
\hline
\end{tabular}

Table 6: Comparative study according to an Apo-Al levels above $1.25 \mathrm{~g} / \mathrm{l}$ and Apo-B lower than $1.25 \mathrm{~g} / \mathrm{l}$.

The diabetes is defined as a condition in which the levels of several factors involved in the processes of coagulation and fibrinolysis, the prevalence of diabetes in this study population was 12 patients $(37.5 \%)$, and for hypertension, it is present in 22 patients (68.6\%) with TEV. These finding is in agreement with the Spanish study of Marcial Martineza et al. [5] but in contrast to two large studies of the past years by Amparo vaya et al. [6] and Ander Holst et al. [7], they said that hypertension and diabetes are not a risk factors for VTE.

A higher BMI is well established such a risk factor for cardiovascular disease and is association with procoagulant state but it is role in TEV disease is controversial $[8,9]$, this study has determined the presence of higher BMI (BMI $\left.\geq 30 \mathrm{~kg} / \mathrm{m}^{2}\right)$ in $43.8 \%$ of patients, but in the Kawasaki et al. $[10,11]$ study the BMI was evenly distributed.

The plasma total cholesterol level has a significant increase in the patient group, also Kawasaki et al. in his both publication and Amparo vaya et al. [6], have confirmed such preliminary finding, but others like the Iranian study, IngeM Schouwenburg et al. [12], Carine Doggen et al. [13] and Everett [14] did not observe a significant difference between thrombosis patients and controls.

We did not find a significant association between Triglycerides plasma level and the risk of VTE, also the two studies of Kawasaki et al. [11], Inge Van Schouwenburg et al. [12], Everett [14] and Zamani have confirmed our finding [15-28], however, Carine Doggen et al. [13], Amparo Vaya et al. [6], Joel Ray et al. [28] and Anders Holst [7] found a significant higher levels in patients.

VTE was associated with low levels of HDL-cholesterol concentration and appeared to be associated specifically with reduced plasma levels of HDL-c and statistically significant $P$ value were found for VTE associated with elevated LDL-cholesterol concentration, in agreement with Hiroshi Deguchi et al. [19], Sabine Eichinger et al. [16], Marian Cheung et al. [17] in contrast to Everet et al. [14] and Keattiyoat Wattanakit et al. [18], they did not find any significant difference.

The difference in the total cholesterol/HDL-C ratio between VTE patients and controls was statistically significant, an elevation was observed in patients group compared with controls subjects and it's the same for LDL-C/HDL-C ratio and non-HDL, these results are consistent with other reports like Hiroshi Degushi et al. [19], in contrast Inge Van Schouwenburg et al. [12] failed to demonstrate a robust link between total Cholesterol/HDL-C ratio, non-HDL and VTE.

On the basis of clinical laboratory plasma Lp (a), we found markedly elevated concentration in patients, so a significant association between Lp (a) plasma levels and the risk of VTE. These results are consistent with other reports; Rosselha Marcucci et al. [20], and Marian Cheung et al. [17]. On other hand, in contrast to Aron Folsom et al. [21] and another studies [22-24].

Statistically significant P value were found for VTE associated with elevated Apo B concentration and with concentration decrease of Apo A1 were observed in patients when compared with controls, our finding is confirmed for both Apo A1 and Apo B in Hiroshi Deguchi et al. study [19] but Sabine Eichinger et al. [16] and Marcial Martinez [5] have uphold this significant association only for Apo A, however, Alanna chamberlain et al. [25] did not find this significant association. Also in a recent study by Inge Van Schowenberg et al. [12] did not show a significant association of Apo B with VTE [26-28].

The difference in the Apo B/Apo A1 ratio between VTE patients and controls was statistically stronger, our results are consistent with Hiroshi Deguchi et al. [19] but Amparo Vaya [6] show that Apo B/Apo A1 ratio is not a risk factor for venous thrombosembolism. We did not observe a significant difference in Apo E levels between patients and controls, and the few studies Jose Diaz [29] et al. and Shuang Li Zhue [26] addressing this issue have failed to demonstrate a link between Apo E and VTE. When dichotomized into higher or lower than 0.91 $\mathrm{mmol} / \mathrm{l} \mathrm{HDL}-\mathrm{C}$ groups, we found a significant association between HDL-C $\leq 0.91 \mathrm{mmol} / \mathrm{l}$ in patients groups, this finding is confirmed by the Spanish study of Garcia Raso et al. [27] but in contrast with him when we regard LDL-C above $4.66 \mathrm{mmol} / \mathrm{L}$.

\section{Conclusion}

This study shows that dyslipidemia can be a possibly risk factor for the venous thrombosis. Further studies are needed to clarify a possible association between venous thrombotic diseases and dyslipidemia and evaluate its implications for clinical practice. The limitations of this study are a small samples size that conditions a relatively small statistical power to prove that dyslipidemia is a risk factor for this disease as considered for cardiovascular disease and their association with the procoagulant state.

The present study shows a significant association between the occurrence of venous thromboembolism and lower levels of HDL-C and ApoA1 and higher levels of LDL-C, Apo-B and Lp(a), but, there were no effect of Triglycerides and ApoE. Nevertheless, these results must be confirmed with a large population study to prove an eventual independent factor for VTE and dyslipidemia.

\section{References}

1. Armand-Perroux A, Barrellier MT (2008) Deep-venous thrombosis Reanimation 17 : Is something new? 736-744. 
Citation: Ben Brik A, Denguir H, Chahed H, Ben Romdhan M, Rzig N, et al. (2016) The Association between Venous Thromboembolism and Lipid Profile in a Tunisian Population. J Vasc Med Surg 4: 276. doi: 10.4172/2329-6925.1000276

2. Rahman A, Islam AM, Husnayen S (2012) Recurrent Deep Vein Thrombosis due to Thrombophilia. Korean Circ J 42: 345-348.

3. Dao MD, Righini M (2013) Thrombose veineuse, Hôpitaux universitaire de Genève, Service de Médecine de premier recours.

4. Sturm W, Sandhofer A (2005) Dyslipidemia and thrombosis: causal relationship or epiphenomenon of sedentary lifestyle? Arterioscler Thromb Vasc Biol 25: e19.

5. Martínez M, Labiós M, Gabriel F (2006) Platelet activation and hypercholesterolemia in the pathogenesis of deep vein thrombosis. Med Clin (Barc) 127: 669-672

6. Vaya A, Mira Y, Ferrando F, Contreras MT, Estelles A (2002) Hyperlipidaemia and venous thromboembolism in patients lacking thrombophilic risk factors. British Journal of Haematology118: 255-259.

7. Holst AG, Jensen G, PrescottE (2010) Risk factors for venous thromboembolism: results from the Copenhagen City Heart Study. Circulation 121: 1896-1903.

8. Ageno W, Prandoni P, Romualdi E, Ghirarduzzi A, Dentali F, et al. (2006) The metabolic syndrome and the risk of venous thrombosis: a case-control study. $J$ Thromb Haemost 4: 1914-1918.

9. Lijfering WM (2011) Relationship between venous and arterial thrombosis: A review of the literature from a causal perspective. Semin thromb Hemost 37 : 885-896.

10. Kawasaki T, Kambayashi J, Sakon M (1995) Hyperlipidemia: A novel Etiologic factor in deep vein thrombosis. Thrombosis Research 79: 147-151.

11. Kawasaki T, Kambayashi J, Ariyoshi H, Sakon M, Suehisa E, et al. (1997) Hypercholesterolemia as a risk factor for deep-vein thrombosis. Thromb Res 88: $67-73$

12. van Schouwenburg IM, Mahmoodi BK, Gansevoort RT, Muntinghe FL, Dullaart RP, et al. (2012) Lipid levels do not influence the risk of venous thromboembolism, Results of a population-based cohort study. Thromb Haemost 108: 923-929.

13. Doggen CJM, Smith NL, Lemaitre RL, Heckbert SR, Rosendaal FR, et al. (2004) Serum Lipid levels and the risk of venous thrombosis. Arterioscler Thromb Vasc Biol 24:1970-1975.

14. Everett BM, Glynn RJ, Buring JE, Ridker PM (2009) Lipid biomarkers, hormone therapy and the risk of venous thromboembolism in women. J Thromb Haemost 7: 588-596.

15. Zamani A, Omrani GR, Lankarani KB (2003) Hyperhomocysteinaemia, hyperlipidaemia and risk of venous thromboembolism in Shiraz. Eastern Mediterranean Health journal.

16. Eichinger S, Pecheniuk NM, Hron G, Deguchi H, Schemper M, et al. (2007)
High-density lipoprotein and the risk of recurrent venous thromboembolism Circulation 115:1609-1614.

17. Cheung MC, Albers JJ, Kennedy H, Deguchi H, Elias DJ, et al. (2010) Association of Apo(a)isoform size with dyslipoproteinemia in male venous thrombosis patients. Clin Chim Acta 411: 1279-1283.

18. Wattanakit K, Lutsey PL, Bell EJ, Gornik H, Cushman M, et al. (2012) Association between cardiovascular disease risk factors and occurrence of venous thromboembolism. A time-dependent analysis. Thromb Haemost 108 : 508-515.

19. Deguchi H, Pecheniuk NM, Elias DJ, Averell PM, John H (2005) High density lipoprotein deficiency and dyslipoprotenemia associated with venous thrombosis in Men. Circulation 112:893-899.

20. Marcucci R, Liotta AA, Cellai AP, Rogolino A, Gori AM, et al. (2003) Increased plasma levels of Lipoprotein(a) and the risk of idiopathic and recurrent venous thromboembolism. The American Journal of Medicine 115: 601-605.

21. Folsom $A R$, Chamberlain $A$ (2007) Lipoprotein (a) and venous thromboembolism Journal List 121: e17-e19.

22. Vormittag R, Vukovich T, Stain M, Lehr S, Minar E, et al. (2007) Lipoprotein (a) in patients with spontaneous venous thromboembolism. Thromb Res 120 15-20.

23. Rodger MA, Le Gal G (2010) Serum Lipoprotein (a) levels in patients with first unprovoked venous thromboembolism associated with subsequent risk of recurrent VTE. Thrombosis Research 126: 222-226.

24. Sirachainan N, Chaiyong C, Visudtibhan A, Sasanakul W, Osatakul S, et al. (2011) Lipoprotein(a) and the risk of thromboembolism in Thai children. Thromb Res 127: 100-104

25. Chamberlain AM, Folsom AR, Heckbert SR, Rosamond WD, Cushman M (2008) High-density lipoprotein cholesterol and venous thromboembolism in the longitudinal investigation of the thromboembolism Etiology (LITE). Blood 112: $2675-2680$

26. Zhu S, Wang Z, Wu X, Shu Y, Lu D (2014) Apolipoprotein E polymorphism is associated with lower extremity deep venous thrombosis: color-flow Doppler ultrasound evaluation. Lipids Health Dis 13: 21.

27. Raso AG (2014) Asociacion entre enfermedad tromboembolica venosa y dyslipidemia. Med cli 143: 1-5.

28. Ray JG, Rosendaal FR (2001) The role of dyslipidemia and statins in venous thromboembolism. Curr Control Trials Cardiovasc Med 2: 165-170.

29. Diaz JA, Ballard-Lipka NE, Farris DM, Hawley AE, Wrobleski SK, et al. (2012) Impaired fibrinolytic system in ApoE gene-deleted mice with hyperlipidemia augments deep vein thrombosis. J Vasc Surg 55: 815-822. 